\title{
Past Privacy
}

\author{
Lars Cyril Nørgaard
}

Privacy is viewed as a feature of the modern era of communication. ${ }^{1}$ In 1844 , the telegraph was introduced, while inventions such as newspaper-folding machines, the typewriter, the gramophone, the telephone, and cinematography all were in place by the century's end. Together with the rise of the tabloid press, these technological developments enabled an increasing commodification of individual lives: the nineteenth-century phenomenon of celebrity chimes with the increasingly precarious position of the individual vis-à-vis the public and its prying eyes. Within this context, the Bostonians Louis D. Brandeis (1856-1941) and Samuel D. Warren (1852-1910) composed a most influential response to the new challenges to the domain of the private sphere. Published in the Harvard Law Review in 189o, their piece identifies photography as a medium that infringes upon privacy and potentially subjects it to public interests: this new invention facilitates an intrusion into the home, which can document private affairs and put them into public circulation. Indeed, the world's first photography had been produced in 1826, and the Eastman Kodak Company would proceed to sell the first commercial camera in 1888 - just two years prior to Warren and Brandeis's seminal formulation of the right to privacy, which imagines a stable balance between the private and the public; the former isolated from the latter unless extraordinary circumstances apply and the common good requires a temporary invasion of privacy.

In its basic outline, this understanding is still the dominant view, even though communication has entered into a new digital era, bringing with it novel privacy challenges. It is important to notice, however, that Warren and Brandeis locate privacy to the home. The right to be let alone concerns life in the family; living such a life constitutes a universal value to society which should be protected by law. This more than implies a perception of personal experiences as something that is not a means to an end, but rather an end in itself. Accordingly, the 189 o formulation of a right to privacy is relative to

1 I would like to thank Michaël Green and especially Mette Birkedal Bruun for reading through this introduction and generously sharing their ideas with me. I also owe thanks to Frank Ejby Poulsen for sharing a survey article on privacy in intellectual history that he is preparing together with Mette Birkedal Bruun. 
historical understandings of selfhood and, especially, of the family. Indeed, this understanding of privacy was prepared in legal cases of the nineteenth century, where similar understandings had been voiced. ${ }^{2}$ Warren and Brandeis also evoke jurisprudence of the late eighteenth century, thereby bringing the historical contours of privacy into fuller view. Their formulation of the concept has its origins in a historical process, where civic identity came into being and separated itself from the workings of the state apparatus and from the intimacy of the family. According to its Habermasian representation, this process began in the seventeenth century and further developed during the eighteenth century, when the private was positioned outside the grip of political authority: the latter instead became fully entangled with the sphere of public deliberation. ${ }^{3}$ The historical accuracy of Habermas's identification of a process of social differentiation has since been called into question. Moreover, the development of a fully-fledged public sphere in the late nineteenth century and the early twentieth century did not entail a clear disassociation of the private life from public concerns. The ideal of a right to privacy was voiced in response to a reality, where the public took a growing interest in disclosing what took place in private. Just like the railway and the postal system supported the circulation of information, the tabloid press and cheap prints made private lives and secret scandals part of the public sphere. Private affaires were also subjected to different modes of analytical reasoning, and the same period that unequivocally allocated sexual behaviour to the nuclear family saw the emergence of a science of such behaviours, that is, a public discourse on private affairs. ${ }^{4}$

Thus, privacy is a constitutive feature of the modern era of communication. From a scholarly perspective, it would nevertheless be a grave mistake if we were to isolate this phenomenon to the nineteenth century. Although the Habermasian analysis of the public sphere has left historians of the seventeenth and eighteenth centuries with more questions than answers, he was surely right to insist that the public is no modern invention: this concept has a long and rich history. The same holds true for privacy. The right to privacy is part of this history and, as it seems today to be slipping out of our hands, we might ask what came before its modern formulation. What was privacy before the right to privacy? What is it, in this perspective, that we still want to protect?

2 This prehistory of the right to privacy is explicitly evoked by Warren and Brandeis and it has been traced by, e.g., Richardson M., The Right to Privacy. Origins and Influence of a Nineteenth-Century Idea (Cambridge: 2017).

3 Habermas J., Strukturwandel der Öffentlichkeit (Frankfurt a.M.: 1962).

4 On the mistaken claim that the Victorian era went silent on matters of sex, see the famous critique by Foucault M., La Volonté de Savoir (Paris: 1976). 
To answer this question, we need to propose a departure from overarching narratives of historical development, and to focus on specific situations and worldviews conjured up in particular sources. We need to tackle the difficult issue that, more often than not, early modern sources further a conceptual framework that has its roots in medieval times and in classical authors of Antiquity. Thus, we face a dual risk of anachronism and atomisation. No right to privacy existed before the nineteenth century, and we are ill-advised to fit the complexities of past societies into the Procrustean bed of universality: privacy is no constant of human history, but rather subject to the changing winds of time. Measuring the scope of such changes is difficult but allows us better to understand our present condition, where we seem of our own volition to give up on our right to privacy. Historically speaking, this paradox is not new, and we encounter several historical situations and practices, where individuals freely disclose their most intimate states in the pursuit of perceived benefits or a sense of communal belonging. Detailing variations and analysing the specifics of past privacies, historical research must abide by the strict standards of scientific communities and express its findings in the technical language that pertains to specific research fields. This implies the risk of an unrestricted relativity, where privacy becomes relative to as many sources within which it can be investigated. It also implies the negative outcome, where privacy is discussed in disciplinary monologue but rarely enters into a dialogue between different disciplinary perspectives.

Past privacy pertains to particular individuals and the lives they lived in specific families, groups, communities, and other collectives. Historically, the forging of such a particularity was entirely circumscribed by public concerns, and the idea of a free development of personality seems a purely modern conception. However, freedom is also a central albeit contested feature of early modern privacy, and we might again say that historical scrutiny greatly improves our understanding of what we say and what we intend to say, when we define present matters of privacy.

In the opening chapter to this volume, METTE BIRKEDAL BRUUN deploys the case of le Grand Condé as a lens for an introduction to the historical study of privacy. Her chapter centres on the two-pronged approach of the Centre for Privacy Studies (PRIVACY): the historical study of terms and the historical study of a phenomenon. A survey of terms, no matter how exhaustive, cannot convey the meaning of words, while the description of a phenomenon - understood 
as the representation of experiential content - falls short of the phenomenon itself. Accordingly, any terminological analysis must focus on several clusters of terms like leisure, withdrawal, solitude, and so on, which in specific sources connect to priv ${ }^{*}$ words, that is, words that derive from the Latin privatus. In addition, the study of a phenomenon cannot access the content of experiences: past phenomena, like privacy, are communicated to us through stylised accounts that convey not the experience itself but an idealised version of a set of meanings that are relevant in a particular societal context. The study of early modern privacy focuses on the analysis of sources as well as on their argumentative conventions and social circumstances. By way of introduction, the complex case of the Prince of Condé illustrates these levels in historical analysis. On one level, the classical understanding of privatus as an individual without civic office remains intact, but, on another level, this understanding is expanded and linked to multiple semantic fields: it lends itself especially to a religious discourse on retreat, which flourished in seventeenth-century France and added layers to the meaning of the priv* word in focus; the vie privée. Thus, the representation of Condé illustrates a multifaceted discourse that offers several different levels of meaning, and which positions the private and the public not as opposites but rather as interconnected spheres of action. On this interpretation, the religious discourse seems especially important to the study of early modern privacy.

At PRIVACY, several researchers pursue the type of research profiled in the introductory chapter. At the same time, we are reaching out to other scholarly communities in order to pursue particular dimensions of early modern privacy, some of which are present in this volume too. The elusive pockets or privacy at court, the networks that rely on more or less private communication and the question of the mediality of early modern privacy as well as its situational character and contextual embeddedness are topics that upcoming publications foreground: Privacy at Sea (ed. Natacha Klein Käfer), Privacy at Court (ed. Dustin Michael Neighbors, Lars Cyril Nørgaard, Ellie Woodacre, and Mette Birkedal Bruun), Privacy in Letter Writing (ed. Michaël Green and Lars Cyril Nørgaard), and Privacy in the Early Modern Low Countries (ed. Ineke Huysman and Michaël Green).

The essays of this volume trace instances of the early modern history of privacy in a wide range of sources. We have organised the essays in four subtopics, each of which highlights particular features of early modern privacy as well as 
the relevant sources and the analytical approaches fit to examine them. Part 1 focuses on different approaches to notions of privacy and the private, highlighting issues of methodology and vocabulary. HEIDE WUNDER takes up the question of gender in relation to notions of privacy. Outlining the complex historiography and its (mis-)representations of the term, Wunder centres on the early modern household as a political unity that, ideally, was to mirror the governmental structure of society. Inside this societal nucleus, the exercise of authority was based on the imperium conjugale and the patria potestas, but authority was also private when it targeted individuals outside of the public arena. This level of privacy did not come with an allocation of separate spaces, where members of the family could entertain private affairs. It was rather a matter of controlling members of this societal body, which seems to exclude privacy understood as individual agency. Instead, the household becomes a discrete entity within the social world: conjugal collaboration and degrees of female agency have to be evaluated on this background.

Within the historical study of privacy, words derived from the Latin privatus take on especial importance: these offer a framework for analysing past notions of privacy as these come to the fore in specific texts. HÉLÈNE MERLIN-KAJMAN warns against anachronism, but also remarks how past meanings that linger in language offer an opportunity to elucidate what privacy might entail. Outlining the meaning of the 'vie privée' in seventeenth-century France, Merlin-Kajman examines a number of textual examples, where she corroborates the broader semantic field of 'privé' as it relates to terms like 'intime', 'familier', and 'particulier'. Maintaining its negative connotation, the private remains a designation of the individual who holds no public office; the term implies a level of suspicion that targets types of relegation, secrecy, withdrawal, and retreat. Individuals renowned for their part in public affairs can entertain a 'vie privée', but these moments of leisure and the locations where they unfold are not situated completely outside the public arena. In comparison to such leisure, the particular identity implies a mereology, where the individual is a part included in the whole. Such an inclusion could be accomplished in the seventeenth century, but the later disjunction of the self and the sphere of the family looms large.

WILLEM FRIJHOFF approaches privacy from a micro-historical perspective on members of the Eelkens family from Bois-le-Duc: these individuals were engaged in the fur trade and active promoters of the Catholic Church. Jacques Eelkens is the first case: he established close connections to the Native Americans and negotiated various agreements; these private relations were put to strategic usage and could readily be disregarded, if this benefited what was perceived to be a greater good. His younger brother, François Eelkens, embodies the family's active stance for Catholicism and the ideal of re-catholicising 
their country: his position within the Oratory of Jesus and his support of the growth of this society spring from what we might call private sentiments, but they implied a conception of the public good. Depending upon the social context, such a conception could be pursued in public or kept out of view: a distinction between private understandings and public appearances comes to the fore in both instances where social identities had to be negotiated. Turning to the case of Swaentgen Joosten and her marriage with Wouter Willemsz, Frijhoff shows how this connection seems initially to have damaged the family's public image. Private decisions had implications for shared identities and therefore had to be resolved publicly.

Mia Korpiola considers the differences between the present legal definition of the right to privacy and past notions of privacy: following von Moos, she defines this consideration as a controlled anachronism. Tracing the terminological development by medieval and early modern jurists, Korpiola shows how the early modern legal scholar David Nehrman illustrates the porous dividing lines between private and public, readily allowing the latter to override the former. Places and spaces could legally be defined as private, but this designation did not entail universal protection: this could immediately be reworked with reference to public concerns. This precarious privacy extends to issues of secrecy and confidentiality, where the circulation of information had to be protected without any formal framework for such protection being in place. The same applies to the household, where owners were protected against a breach into their private space, but such breaches were defined in a polyvalent terminology. Likewise, family life was surrounded by an embryonic level of protection during the early modern period, if we evaluate it by the light of later developments.

Part 2 focuses on specific instances that seemingly highlight privacy and the private by way of traversals and transgressions: the sources discussed in this part are characterised by their direct or indirect representations of the private as truths about the self that remain forever hidden or are disclosed to strategic ends.

Lee Palmer Wandel reads the moment of Communion as it comes to the fore in the Siebenhirter Hours. The receiving of the Eucharist constitutes a composite event with a variety of possible outcomes for its recipient; the image implies an understanding of the matter of the host as instable, as relative to the question of the votary's worthiness. This question of worthiness unfolds in a sequence of nested zones, ranging from the church space to the mouth of the individual recipient. These zones integrate inside with outside, sacred with secular, private with public. During the medieval period and the early modern period, levels of such integration were central to the Mass. Turning 
to William Durand's hermeneutics elaborated in the Rationale divinorum offciorum, Wandel shows how the depicted figures in the Siebenhirter Hours can be identified as three recipients and four men vested with different levels of sacerdotal authority. Within the visual argument, the first three show that the words of consecration - represented by the other four figures - cannot ensure that Christ is present in the Host: the public setting of this ritual implies a private element, where the worthiness of individual communicant remains indiscernible and is activated only in the intimate moment when mouth and host, believer and God touch.

ANNE RÉGent-SUSINI takes up the genre of funeral sermons in early modern France. The oraisons funèbres move beyond the private-public divide, and this transgression comes to the fore in their inherent proxemics: linguistic markers appeal to both their immediate addressees (the listeners) and to other spheres of addressees (readers). This epideictic genre also involves a biographical element, where the life of the deceased has to be measured by the standards of the common good. This ancient rhetorical exercise takes on new meaning, however. The growing suspicions towards public appearances inform preachers, as they recognise how the simulation of virtues looms large in all public appearances: the site where virtues can be verified becomes the domestic domain and the self's interior space. Régent-Susini thus shows how, long before the nineteenth century, private lives are privileged as having a particular authenticity, but also that this authenticity is ambiguous: it is located in an interior that is not transparent and cannot straightforwardly be described in words. The private resides in the zone between the inaccessible secrets of the self and its public show of virtue.

MATHIEU LAFLAMme explores eighteenth-century legal complaints by pregnant women, who had been abandoned by their lovers. Such documents, in casu from the city of Toulouse, uncover intimate details about the lives of couples and premarital sexuality. As historical sources, the complaints and the ensuing legal proceedings document how servants, families, and neighbours could trespass on the private lives of individuals. However, the complaints themselves also follow an apparently fixed itinerary, where the couples' sexual relations are tolerated within the community because these relations are seen in light of a future marriage: sexual intimacy becomes problematic, when this future turns out to have been an empty promise. In this situation, the complaints and their disclosure of private states can be seen as a rudimentary level of female agency. Subjecting themselves and their emotional lives to the standards of a legal process, the women's filing of complaints testifies to the attempt to protect social dignity and restore financial stability. 
Focusing on three egodocuments written by early modern Jewish Amsterdammers, MichaËL GREEN explores notions of privacy within the urban milieu of this specific religious minority. Egodocuments offer a personal perspective that allows for the understanding of how privacy was perceived by an individual. Isaac de Pinto, Abraham Chaim Braatbard, and Moses Salomon Asser respectively wrote a family history, a chronicle of daily events, and an autobiography. The situation of the Jews in the United Provinces was rather comfortable - they were free of persecution and generally enjoyed a peaceful life. Yet, they felt that their situation could easily change. Jewish leaders, who were well aware of the dangers, made every effort to prevent persecution, often by allowing gentiles into their religious services and homes. These three egodocuments demonstrate precisely such strategies at work: how Jews maintained their privacy within the community on the one hand, and how they were willing to sacrifice it in order to secure their position in the country over time on the other.

Part 3 explores the private and privacy in relation to secrecy, knowledge, and authority. The legitimacy and success of, for example, merchants, scholars, and healers relied on careful wielding of secrecy and disclosure, on the distribution of information and its necessary protection. In societal structures, where interactions were highly controlled, the private attracted suspicion, but also facilitated levels of influence upon the public.

Thomas MAX SAFLey poses a question about the irony of secrecy within the business community of the early modern period. This community required a level of secrecy, but also recognised the strategic value of disclosing secret matters, while the surrounding world viewed such disclosures as an attack on the very fabric of society. In the late medieval period and during the sixteenth century, business charters rarely held a secrecy clause, though these clauses would become increasingly common during the ensuing century. An early example is the 1515 charter for the Höchstetter company, and Safley demonstrates how this universal prescription of secrecy was nevertheless applied in a very selective manner; special circumstances could also allow for the disclosure of secrets. As such, the historical analysis of the management of secrets turns out to be a slippery topic that obstructs overarching narratives of societal development. It remains intrinsically linked to personal perspectives, and the private interest here becomes a historical level of analysis that must be elucidated in the scrutiny of specific sources.

IVANA BIČAK explores early modern the culture surrounding early modern scientific experimentation and its entanglement of the private and the public. According to Thomas Sprat, scientific trials are private events that become a real experiment, when the set-up is displayed before witnesses for scientific 
validation: this spectatorship verifies the public and scholarly value of private undertakings. However, some experiments were not fitting for the public because they required an environment that made public viewership difficult. Therefore, semi-public experiments could be undertaken. In Robert Boyle's written accounts of scientific trials, the author fashions a different solution to this very problem: he publishes private observations and thereby secures an audience for his trials. This virtual mode of witnessing would also provide ample material for satire, and Bičak demonstrates that the same attention to detail, which was required to ensure public credibility, could be turned on its satirical head; the private become a locus of parody.

NATACHA KLEIN KäFER analyses the complex relation between healer and patient and its paradoxes of confidentiality. Her late medieval and early modern cases show how women would provide communities with expertise, but how their profession as healers could also make them subject to accusations of witchcraft and infanticide. In such instances, knowledge became precarious: healers possessed private information about their patients, and trial records show how confidentiality was construed but also how it could be breached with a view to strategical ends. During investigations that might well have involved torture sensitive details about private lives would be exposed. To save themselves from the stake, the accused could disregard confidentiality, essentially putting private information into public circulation.

HANG LIN identifies two types of prints that date to the late Ming dynasty and illustrate changing understandings of the public and the private. Collections of examination essays support the creation of a community of intellectuals, who served the political end of reproducing the empire's cultural and social ideology. During the first half of the seventeenth century, the publication of such essays would develop and begin to undermine imperial authority in the intellectual realm: the essays in their original form became accessible to the public, and the orthodox ideal fragmented into several private interpretations. With the ensuing proliferation of unorthodox commentaries, the Ministry of Rites imposed regulations that publishers attempted to work around by means of paratextual devices. The printing boom in Ming China reshaped and enhanced the public realm of deliberation and knowledge production, which made private opinions and small communities more present in the social world.

Part 4 engages with a spatial approach to privacy and the private. The contributions in the volume's final part target physical, mental, and represented spaces that exemplify forms of segregation and throw light on early modern notions of privacy and the private - be that by negation or affirmation.

How and why did Catholic votaries reflect on the relation between the public and private lives of Christ? WALter S. Melion unpacks this question on 
the basis of the Vita S. Ioseph beatissimae Virginis sponsipatriarcharum maximi iconibus delineata ac versiculis ornata. This manuscript interpolates two print series: the Cor Iesu amanti sacrum that shows how Jesus comes to dwell within the human heart, making it indistinguishable from his own, and Adriaen Collaert's Vita S. Joseph, which chronicles the life of the Holy Family, showing how Joseph and Mary instructed Jesus in the use of household and workshop implements. By way of this interpolation, familiarity with material things proves crucial to the heart's familiarity with Jesus; the artisan Joseph, assisted by Mary, passes on his manual skills in the public setting of the workshophome, and conversely, Jesus skillfully fashions his father's heart into a spiritual home and workshop within the privacy of which he comes eternally to dwell. The descriptive, public imagery of the Vita S. Joseph is seen to lead to the allegorical, private imagery of the Cor Iesu; and mutatis mutandis, the symbolic allegory of the heart infuses or, better, saturates the scenography of the Vita.

MAARTEN DELBEKE investigates the architectural underpinnings of private devotion and public edification as these come the fore in Bernini's programme for the Cornaro-chapel. This investigation is framed by a reading of the Gabriele Paleotti's Discorso intorno alle immagine sacre e profane that discusses the public function of religious art and places this function on different levels of social reality. Paleotti remarks how any painting of a sacred subject transcends the reasons why it was commissioned: religious art cannot be reduced to private interest; neither the patron's wishes nor the artist's intention exhaust its purpose. Instead, this art form always speaks to the public concern and shared human obligation to glorify God. Delbeke's analysis of Bernini's architectural decisions furthers this observation. The transverberation of Teresa of Avila relates a most intimate experience, and this intimacy translates into a niche that is placed under stress of transformation: this niche also evokes the use of architectural metaphors in textual representations of mystical experiences, which Teresa masterfully utilised in her writings. Furthermore, the effigies of male members of the Cornaro family, including the patron of the chapel, frame the transverberation, but these male figures work in support of the private quality of the saint's experience.

LARS CYRIL NøRGAARD offers a close analysis of a funeral sermon by the bishop of Zealand, Jesper Rasmussen Brochmand. Transitioning from a public event - an oration delivered to an audience - to a published event, this speech makes private information available to the public. This transition, however, filters such information through a social model of identity. A list of rhetorical loci allows the speaker to praise past actions and make them into manifestations of virtues. Based on this epideictic genus, the sermon introduces reported speech that is not in the public domain: Brochmand shows the dying individual where nobody would otherwise have seen him; and private moments of intense 
soteriological importance confirms a public image. Individualised by death, personal experiences are evoked in support of exemplarity.

VAleria Viola scrutinises the complex renovation of the Palazzo di Valdina in Palermo, where boundaries between different structures had to be reconfigured. Political interests and social concerns heavily influenced the general scope of this reconfiguration, but it also involved the construction of new locations that seem places for intimacy and privacy. These locations were developed for a palace that consisted of a complex of pre-existing houses: a new apartment facilitated what appears as isolation, but close examination reveals that this space secured an important linkage of the palace and the church room of San Tomaso. Issues of visibility circumscribe this opening into the sacred space, and private devotion becomes part of the political staging of identity. Furthermore, the apartment's withdrawn position within the palace reproduces a number of social hierarchies relating to rank and gender. Thus, the private cannot be isolated from political realities and strategies; it is part of the public sphere.

Entering into what she describes as a lost world, MARIAN RoTHSTEIN concludes the volume with an elaborate reflection on the limits imposed on the private in sixteenth-century France, following the undeniable observation that privacies of the past did not belong to the domestic sphere. A terminological approach further reveals that particularity in its sixteenth-century usage was no synonym for the private. This notion rather denotes belonging to a shared identity, whereby private and public intersect in multifarious ways, and the former appear entirely circumscribed by the latter. However, Rothstein maintains that early modern intimacy, while difficult to trace, nonetheless existed. Likewise, the realm of the private existed, but it has a narrow scope if measured by the fluctuating standards of modern customs.

Working through widely different sources, and deploying the analytical approaches of different scholarly fields, the scholars contributing to this volume show that early modern notions of privacy and the private are not fixated, stable, or clear-cut, but rather malleable, ephemeral, and situational. Before the right to privacy of the late nineteenth century, a plurality of privacies existed that had no legal protection but permeated the cultural imaginary. Rather than aiming to reach conceptual models or robust definitions, we need carefully to reconstruct the scope and scale of such privacies. In different ways, the contributions in this volume testify to the fact that instances of early modern privacy must be examined with such a precise view to the individual sources and their respective contexts. The concept of privacy has no universal application, but its concrete elaboration is revealing of particular social interests and concerns: notions, instances, spaces, and sources pertaining to early modern privacy and the private, open a multitude of facets of early modern existence. 